\title{
Comparison of differences in post-cesarean section infection following a three-dose prophylactic antibiotic regimen and no prescription of antibiotics, a randomized clinical trial
}

\section{ARTICLE INFO}

Article Type

Clinical Trial

\section{Authors}

Mojghan Karmnia Far ${ }^{1}$, MD*

Abootaleb Saremi ${ }^{2}$, iD MD

Mohammad Reza Nateghi ${ }^{2}$, (D) MD

Maryam Sanaye Naderi ${ }^{2}$ B.S

${ }^{1}$ Sarem Fertility and Infertility Research Center (SAFIR), Sarem Women's Hospital, Iran University of Medical Science (IUMS), Tehran, Iran.

2 Sarem Fertility \& Infertility Research Center (SAFIR) \& Sarem Cell Research Center (SCRC), Sarem Women's Hospital, Iran University of Medical Sciences (IUMS), Tehran, Iran.

\section{*Corresponding Author}

Address: Sarem Women Hospital, Basij Square, Phase 3, EkbatanTown, Tehran, Iran. Postal code:1396956111

Phone: +98 (21) 44670888

Fax: +98 (21) 44670432

Dr.karamnia@sarem.org

\section{ABSTRACT}

Aims: Inappropriate administration of antibiotics, in addition to increasing costs and drug reactions, can lead to the spread of resistant bacterial infections. Some studies have suggested that preoperative antibiotics are effective in reducing surgical infection. Other studies have shown that there is no difference between prescribing one-dose and three-dose antibiotics after surgery. Due to the lack of agreement on the use or non-use of antibiotics after surgery, the present study was performed to determine the effectiveness of antibiotics after elective cesarean section in reducing the rate of infection.

Material and methods: In this randomized clinical trial, 63 patients who were candidates for elective cesarean section received a dose of antibiotics (Cefazolin, 2g, intravenous injection) one hour before surgery. They were then randomly divided into two groups. The intervention group $(n=37)$ received three doses of antibiotics (Cefazolin, $2 \mathrm{~g}$ every $6 \mathrm{~h}$, intravenous injection), while the control group $(\mathrm{n}=26) \mathrm{did}$ not receive any postoperative antibiotics. Patients were followed up for 40 days after surgery and the effectiveness of these two methods in preventing infection was investigated.

Results: There was no statistically significant difference between the intervention group and the control group in any of the parameters of age, weight, height and body mass index. Also, there was no significant difference between the rate of infection after cesarean section between the group receiving antibiotics and the control group $(P>0.05)$.

Conclusion: Findings of this study showed that receiving antibiotics after the cesarean section has no effect on the prevention of surgical infection. According to the results of this study, as well as the increase in microbial resistance to antibiotics and treatment costs, antibiotics can be discontinued after elective cesarean section.

Keywords: Infection, Cesarean Section, Antibiotics, Prophylaxis, Cefazolin, Randomized Clinical Trial (RCT)

\section{Article History}

Received: April 24, 2020

Accepted: May 25, 2020

e Published: February 13, 2021

Copyright(C) 2020, ASP Ins. This open-access article is published under the terms of the Creative Commons Attribution-Noncommercial 4.0 International License which permits Share (copy and distribute the material in any medium or format) and Adapt (remix, transform, and build 
بيماران تا •f روز يس از جراحى يِيَيرى شدند و تاثير اين دو روش در

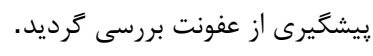

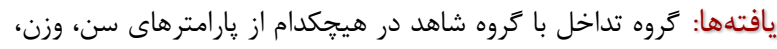

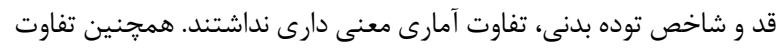

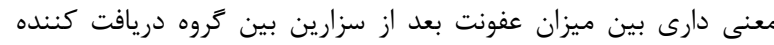

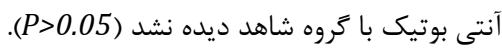
بحث و نتيجهَيرى: يافتهاى اين مطالعه نشان داد كه دريافت

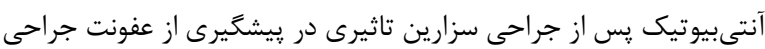

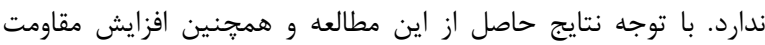

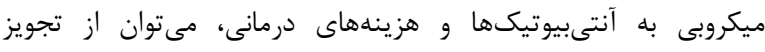
آنتىبيوتيك پِ از جراحى سزارين انتخابى صرف نظر كرد.

كليد وارمها: عفونت، جراحى سزارين، آنتىبيوتيك، يروفيلاكسى، سفازولين، كارآزمايى بالينى تصادفى إنى

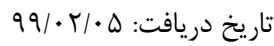

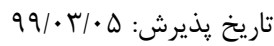

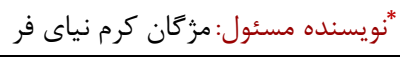

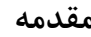

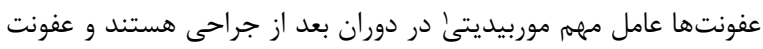

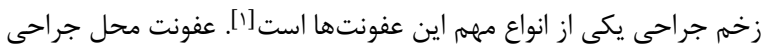

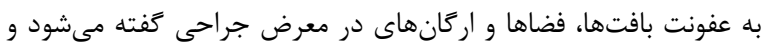

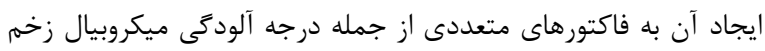

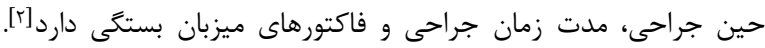

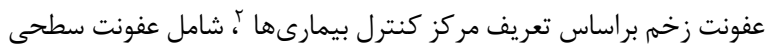

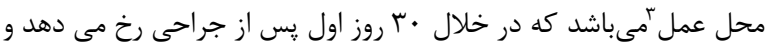

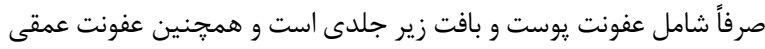

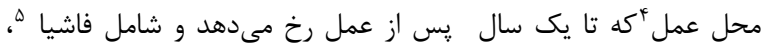

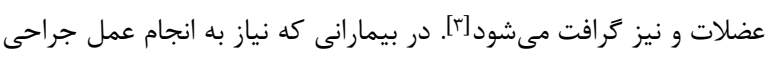

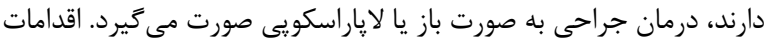

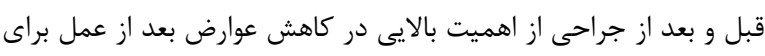

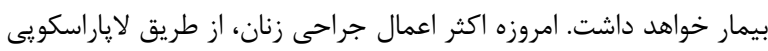

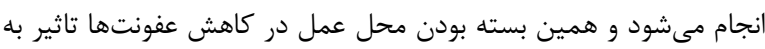

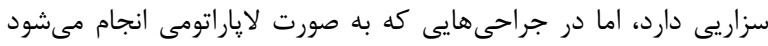

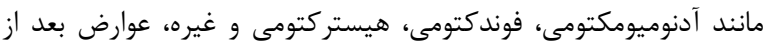

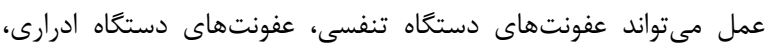

Deep Surgical Site Infection (DSSI)

Fascia
مقايسه تفاوت در عفونت پيس از جراحى سزارين، بدنبال استفاده از رزيم ييشگيرانه سه دوز آنتىبيوتيك در مقابل عدم تجويز آنتىبيوتيك، يك كار آزمايى بالينى تصادفى

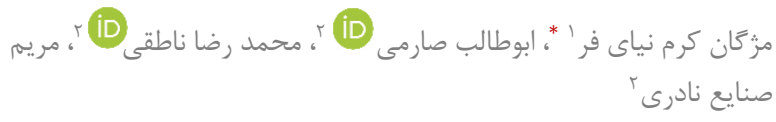
' مركز تحقيقات بارورى و نابارورى صارم، بيمارستان فوق تخصصى صارم،

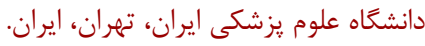

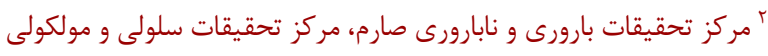

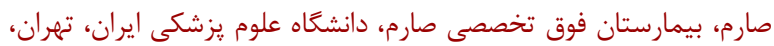

جكيده اهداف: تجويز نامناسب آنتىبيوتيك علاوه بر افزايش هزينه و واكنشهاى دارويى، موجب گسترش عفونتهاى مقاوم باكتريايى مى گردد. برخى

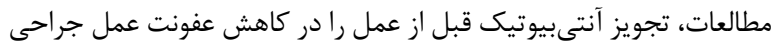

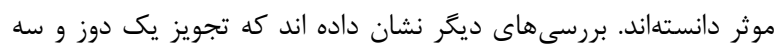

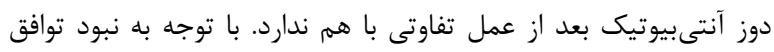

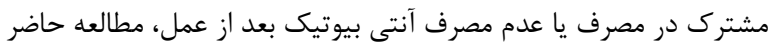

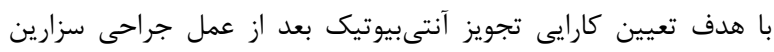
انتخابى، در كاهش ميزان عفونت انجام كرديد.

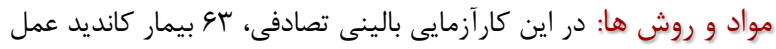

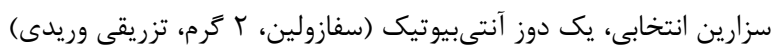

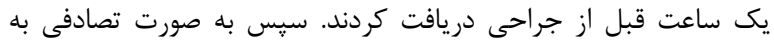

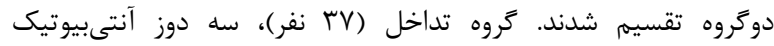

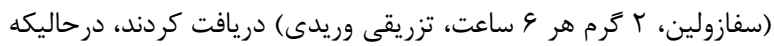

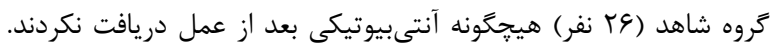

Morbidity

Centers for Disease Control (CDC) Superficial Surgical Site Infection (SSSI) ${ }^{r}$ 
مطالعه شدند. براى محاسبه حجم نمونه، ميزان متغيرهايى نظير شيوع كلى آلى

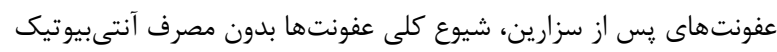

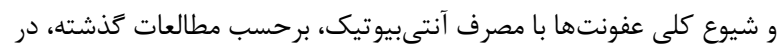

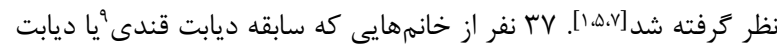

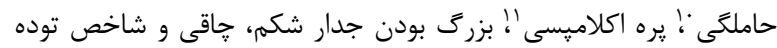

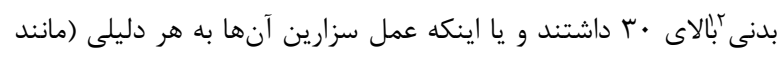

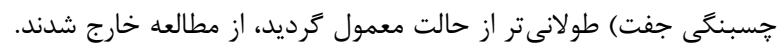

(نمودار شماره () جنى (ن)

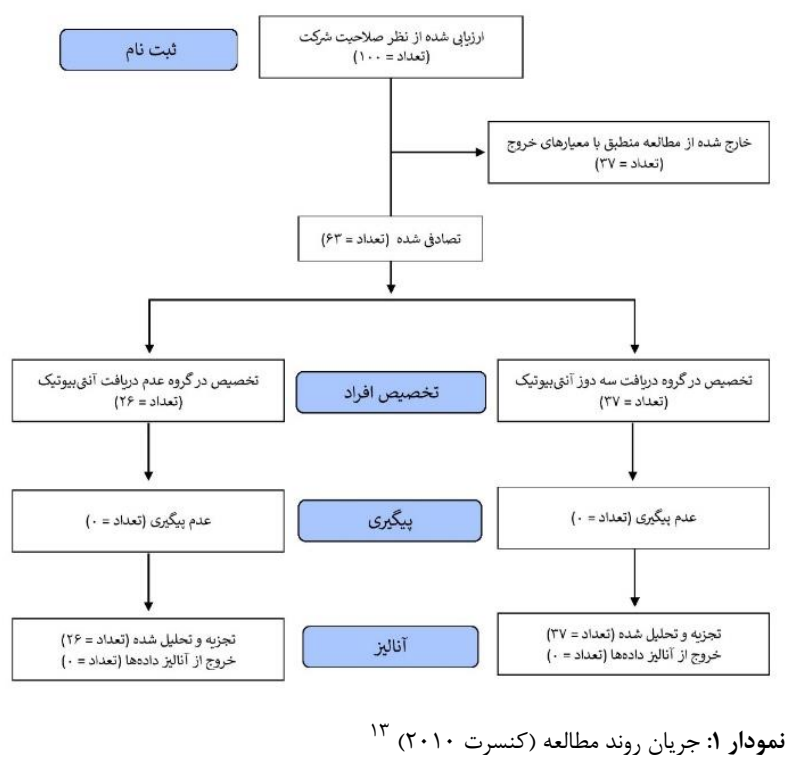

باء زن باردار، يس از مد نظر قرار دادن معيارهاى ورود و خروج، در مطالعه

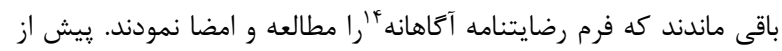

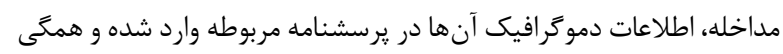

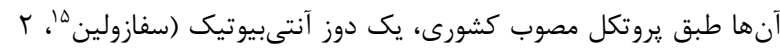

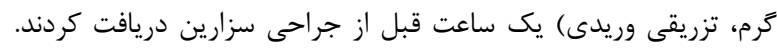

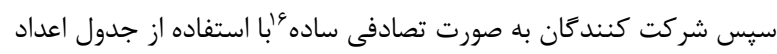

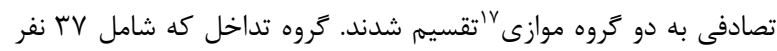

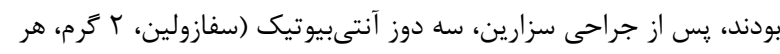

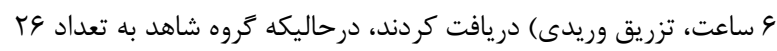

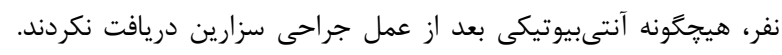

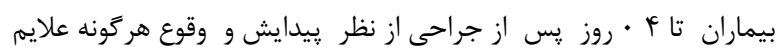

Body Mass Index (BMI) CONSORT Flow Diagram of RCT 't Informed Consent Form 's: Cefazolin Randomization Parallel Study Design
عفونت محل زخم، سلوليت لكن، آبسهها، فاشئيت نكروزان و و غيره باشد.

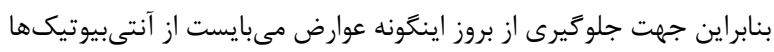

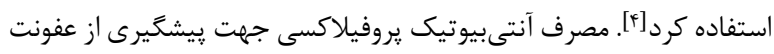

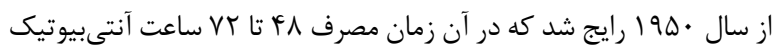

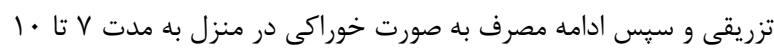

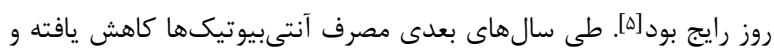

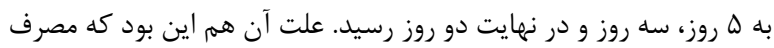

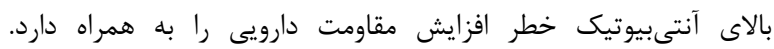

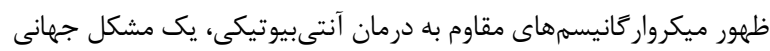

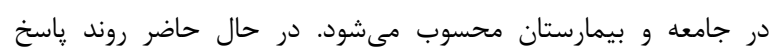

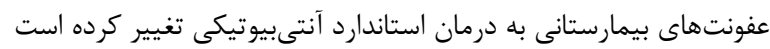

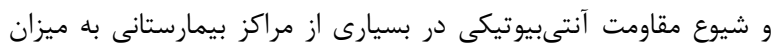

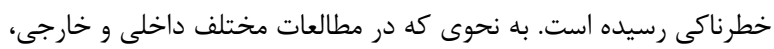

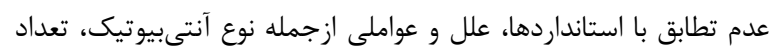

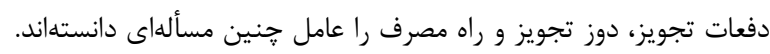

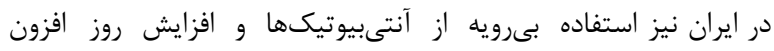

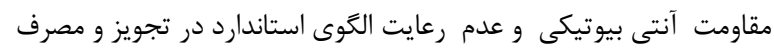

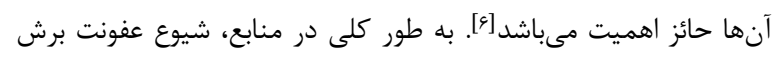

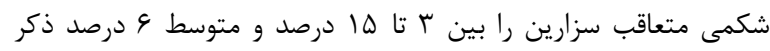

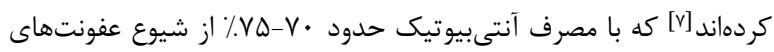

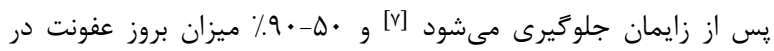

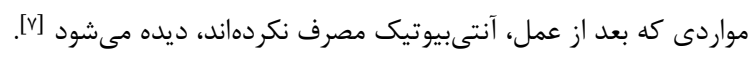

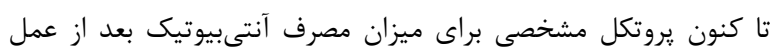

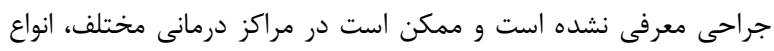

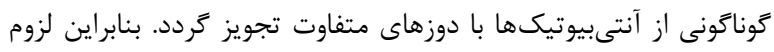

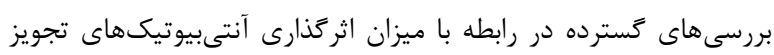

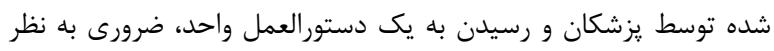

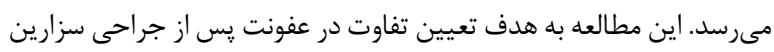

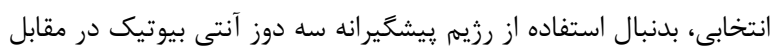
عدم تجويز آنتى بيوتيك، طراحى و به انجام رسيد.

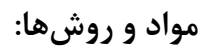

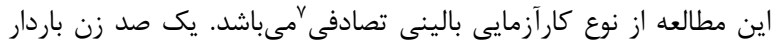

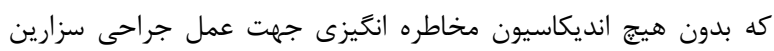

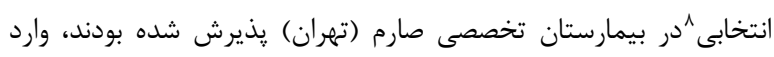




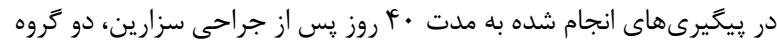

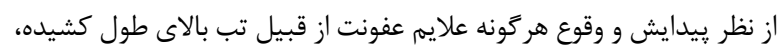

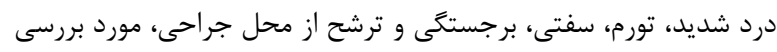

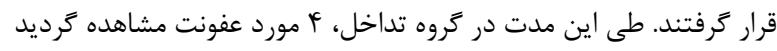

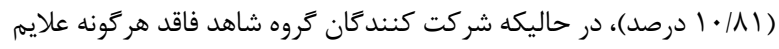

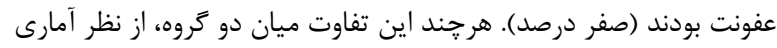

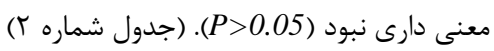

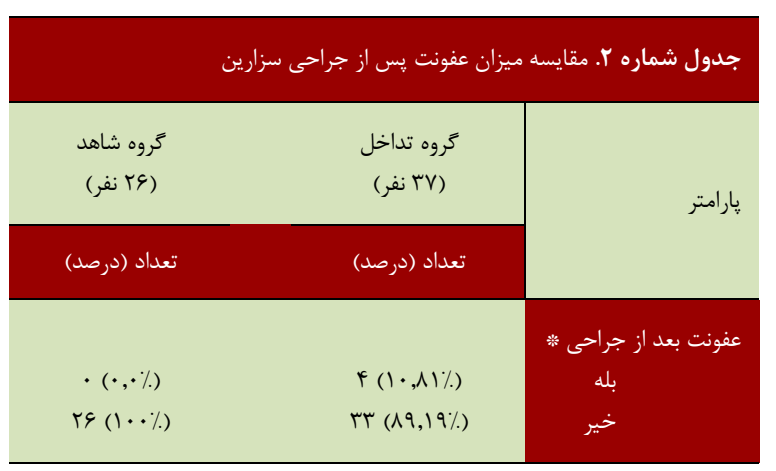

" برحسب آزمون آمارى دقيق فيشر، تفاوت آمارى معنى دارى ديده نشد (P>0.05) :

\section{بحث و نتيجهل}

نتايج مطالعه حاضر نشان داد كه دريافت آنتىبيوتيك يس إن از سزارين و عدم

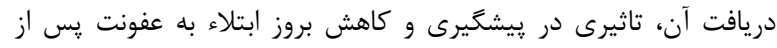

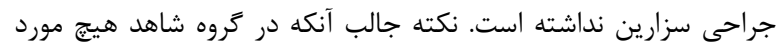

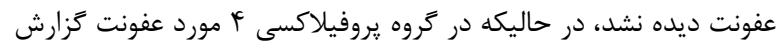

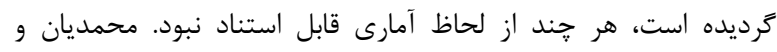

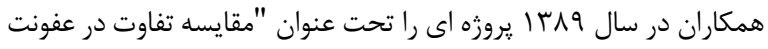

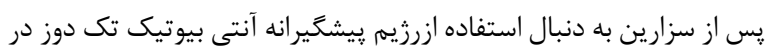

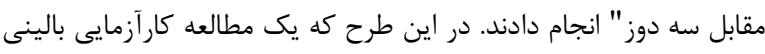

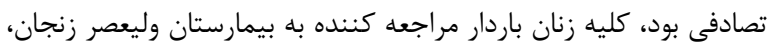

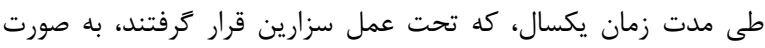

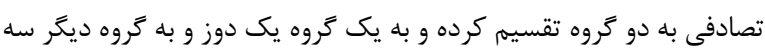

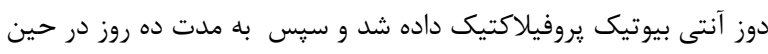

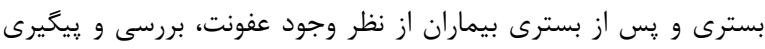

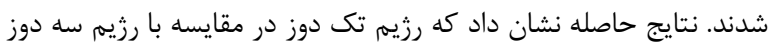

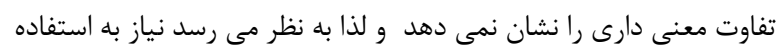

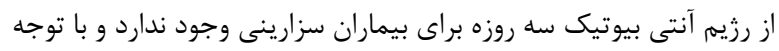

عفونت از قبيل تب بالاى طول كشيده، درد شديد، تورم، سفتى، برجستگى

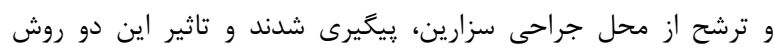

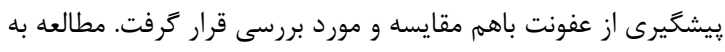
صورت يك سو كور انجام يذيرفت به طوريكه جمع آورى دادهما مانها و آناليز

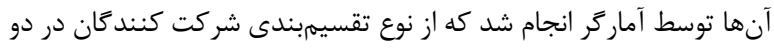
كروه مداخله و شاهد اطلاعى نداشت. دادههاى مطالعه توسط نرمافزار SPSS مُورد تحليل قرار كرفت. از جدار جداول

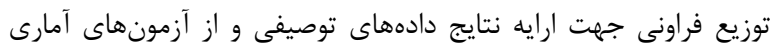

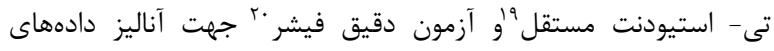

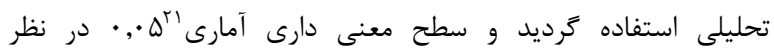
كرفته شد.

\section{نتايج:}

در اين يزوهش بو زن باردار، بدون هيج انديكاسيون مخاطره انكيز جهت

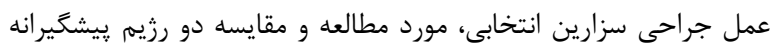

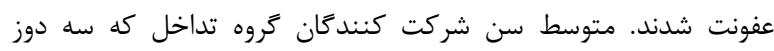

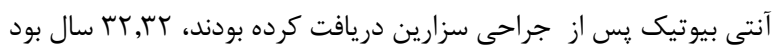

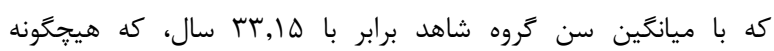

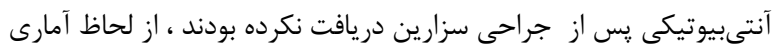

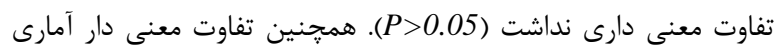

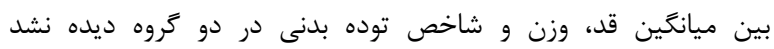

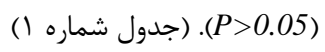

\begin{tabular}{|c|c|c|c|}
\hline \multicolumn{4}{|c|}{ جدول شماره ا. مقايسه سن، قد، وزن و شاخص توده بدنى } \\
\hline تفاضل مينكا & كروه شاهد & 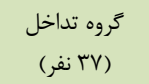 & \multirow{2}{*}{ ليارامتر } \\
\hline $\begin{array}{l}\text { منفى) } \\
\text { (مقادير }\end{array}$ & (انحراف معيار) & (انحراف معيار) & \\
\hline$(\cdot, \lambda \Gamma)$ & $r, \Delta(\Delta, \mid f)$ & $r, r, r(\xi, T \cdot)$ & سن (سال) * \\
\hline$r$, TL & $\mid \varepsilon r, \cdot(\varphi, r \mid)$ & $194, r \Delta(\Delta, 19)$ & قد (سانتىمتر) : \\
\hline$r, \Lambda \Lambda$ & $\vee V, १ ९(1 \cdot, \Delta \Lambda)$ & $\Lambda \cdot, \wedge f(11, \Gamma \varphi)$ & وزن (كيلوَرم) * \\
\hline$\cdot, 11$ & $r V, 99(r, 94)$ & $r V, \wedge V(r, \Delta \cdot)$ & شاخيلوكرم/مترمربع) تدان \\
\hline
\end{tabular}

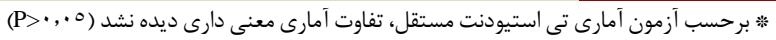

IBM SPSS Statistics for Windows, version 22 (IBM
IBM SPSS Statistics for Windows, version 22 (IBM
Corp., Armonk, N.Y., USA).
Independent T-Student Test

IBM SPSS Statistics for Windows, version 22 (IBM
Corp., Armonk, N.Y., USA).
Independent T-Student Test
Fisher's Exact Test Significance Level 
غير انتخابى نيز به انجام برسد، تا بتوان به نتيجه گيرى فراتر و جامعترى در

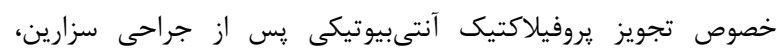
دست يافت.

\section{تشكر و قدردانى:}

از لطف بىدريغ كاركنان محترم بيمارستان و مركز تحقيقات بارورى و و و

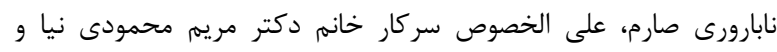
همجنين شركت كنند

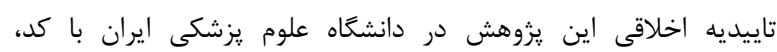
IR.IUMS.REC.1396. 23099608822

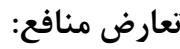

در اين مطالعه تعارض منافع وجود نداشت.

\section{سمهم نويسند مَان:}

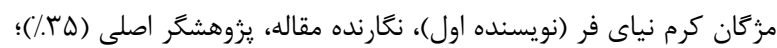

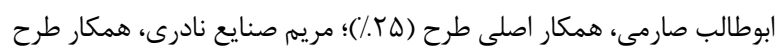

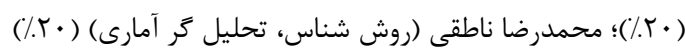

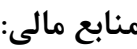

هزينه هاى يزوهش توسط مركز تحقيقات بارورى و نابارورى صارم تامين

\section{شناسه اركيد نويسندكًان (ORCID):}

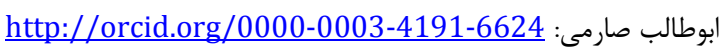
http://orcid.org/0000-0001-5754-0516 محمدرضا ناطقى صاردي:

منابع

1. Yazdani S, Bouzari Z, Abedi Samakoosh M, Nazari A, Daryabari A. Risk factors incidence of surgical wound infection following abdominal hysterectomy. J Gorgan Univ Med Sci. 2014;15(4):90-4.

2. Afhami S, Esmailpour Bazaz N, Boujar Arani N, Sayadi L. Antibiotic prophylaxis before surgeries. Iran J Surg [Internet]. 2011;19(3):2832. Available from:
به ايجاد مقاومت دارويى و زيان اقتصادى، استفاده از تك دوز براى

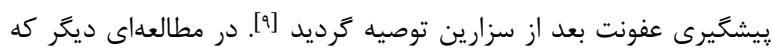

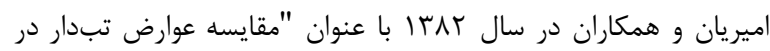

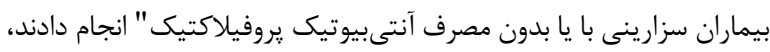

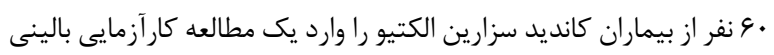

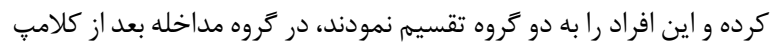

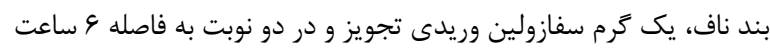

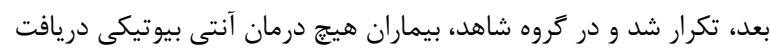

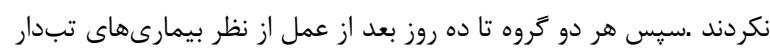

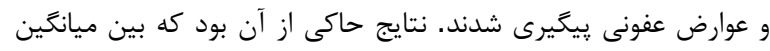

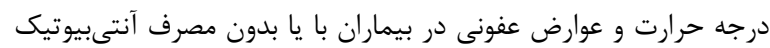

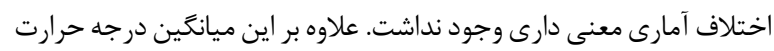

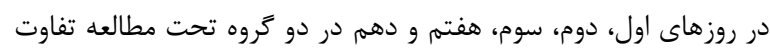

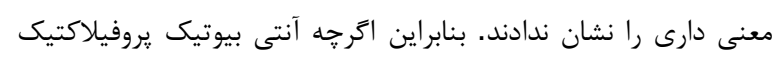

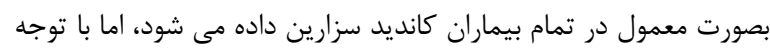

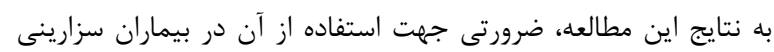

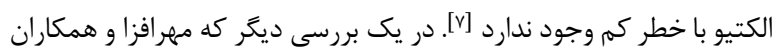

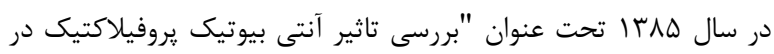

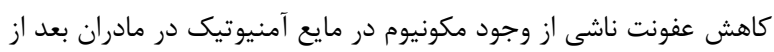

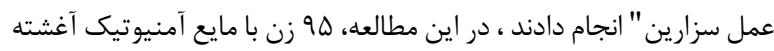

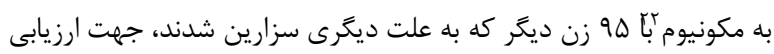

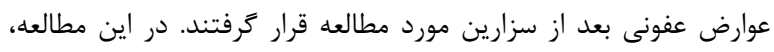

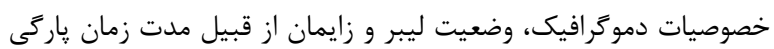

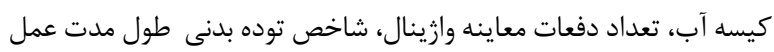

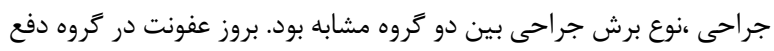

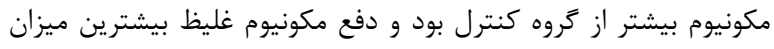

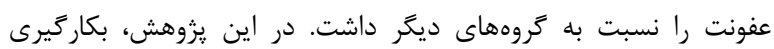

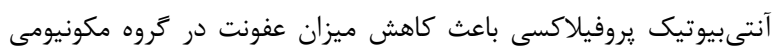

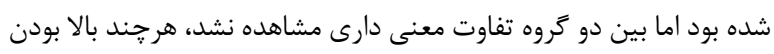

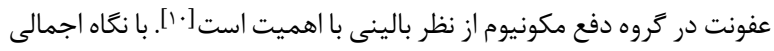

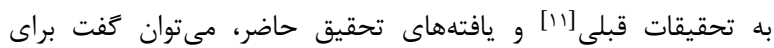

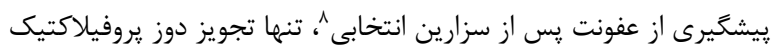

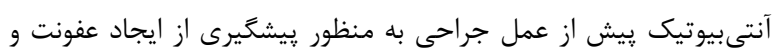

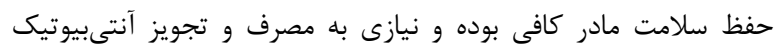

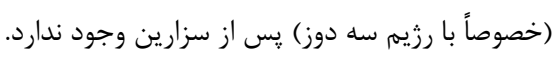

\section{بيشنهادات:}

با توجه به اين كه مطالعه حاضر بر روى سزارينهاى انتخابى انجام يذيرفت،

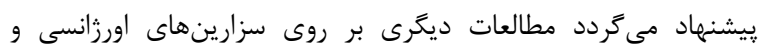


infections in patients with meconium stained amniotic. Avicenna-J-NursMidwifery-Care [Internet]. 2006 Sep 1;14(1):45-55. Available from: http://nmj.umsha.ac.ir/article-1-1016en.html

11. Ahmadi S, Rahmani E, Ahmadi K, Bahreman B. Comparison of single dose of cefazolin versus single dose of cefazolin plus seven days cephalexin prophylactic therapy in postoperative infections after elective cesarean section and immediate adverse effect of antibiotic on infants. Iran J Obstet Gynecol Inf
https://www.sid.ir/en/Journal/ViewPaper. aspx?ID $=253922$

3. Rahmani N, Kerman Sarav M, Sayadi S, Khalilia A. Effect of Prophylactic Antibiotics in Preventing Wound Infection in Herinoplasty with Inguinal Mesh in Lichtenstein Method. J Maz Univ Med Sci. 2012;22(90):88-93.

4.

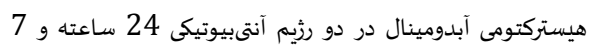

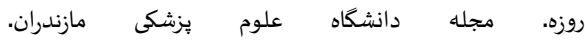
9-34:(42)14;1383.

5. Akbari H, Elyasi L, Akbari R, Ghaempanah Taag Abadi M, Amirian M. Evaluation of prophylactic antibiotics in surgery compared to the national antibiotic guideline. J Sabzevar Univ Med Sci. 2016;22(6):1071-9.

6. Raeeszadeh M, Berenjian S. Prescription of Antibiotics Before and After Surgery at the Surgical Wards of Isfahan Amiralmomenin Hospital Compliance with the Standard Guidelines. hrjbaq [Internet]. 2016 Sep 1;1(3):133-40. Available from: http://hrjbaq.ir/article-1-46-en.html

7. Amirian M, Peironaziri GR, Hejazi M. A comparison of febrile complications in cesarean section with or without prophylactic antibiotics. Hormozgan Med J. 2003;7(2):84-7.

8. Fonseca SNS, Sofia MH, Quintana S, Nogueira FDS, Levin AS. Successful control program to implement the appropriate antibiotic prophylaxis for cesarean section. Rev Inst Med Trop Sao Paulo [Internet]. 2008 [cited 2021 Feb 4];50(2):79-82. Available from: https://pubmed.ncbi.nlm.nih.gov/184880 85/

9. Mohammadian F, Mobaien A. Comparison of post cesarean infection after single dose versus three doses of prophylactic antibiotic regimen. Iran South Med J [Internet]. 2013 Apr 1;16(1):29-36. Available from: http://ismj.bpums.ac.ir/article-1-388en.html

10. Mehrafza M, Roushan Fekr S, Oudi M. The effect of prophylactic antibiotics in decrease the risk of post cesarean 